\title{
Community Cultural Development for Social Change: Developing Critical Praxis
}

\author{
Christopher C. Sonn
}

Victoria University

\section{Amy F. Quayle}

Melbourne, Australia

\begin{abstract}
A growing number of writers in community psychology have called for re-claiming the radical impetus that inspired the development of the field. In this article we describe a program of work facilitated by a community cultural development agency that uses community arts practice to create, promote and improve opportunities for participation, network development, and empowerment in rural Western Australian communities. The program of work we describe in this article sits within a broader systematic effort aimed at social change in a specific geographic region of Western Australia, and reflects a particular commitment to challenging the continuing social exclusion of Aboriginal people in postcolonizing Australia. Informed by writing within community and liberation psychologies, we discuss three community arts projects and highlight the key concepts of participation, power/empowerment and situated knowing in our examination of community cultural development as participatory methodology. We emphasize the iterative and generative nature of arts practice and argue that community cultural development practice is often aimed at both instrumental as well as transformative outcomes. We suggest that the transformative dimensions require a critical theoretical lens to help explicate the operations of power and coloniality in the micro settings of community practice.
\end{abstract}

Keywords: community arts, community cultural development, praxis, Indigenous, participation

\section{Introduction}

A growing number of writers in community psychology have called for re-claiming the radical impetus that inspired the development of the field. Some of this is reflected in calls for a critical community psychology (e.g., Davidson, et al. 2006; Kagan, Burton, Duckett, Lawthom, \& Siddiquee, 2011; Kagan \& Burton, 2000), psychologies of liberation (Burton \& Kagan, 2005; Montero \& Sonn, 2009; Watkins \& Shulman, 2008; Watts \& Serrano Garcia, 2003) and the current interest in critical community practice (e.g., Henderson, 2007). Critical community practice is "action based on critical theorizing, reflection, and a clear commitment to working for social justice through empowering and transformative practice" (Henderson, 2007, p. 1). 
In this article, we describe a community-based program of work led by Community Arts Network Western Australia (CAN WA), a community cultural development agency that creates, promotes, and improves opportunities for participation, network development, and community empowerment by:

- Engaging in arts and cultural practice with diverse Western Australian communities (CAN Productions);

- Working with artists and practitioners to advance community arts and cultural development through training and mentoring opportunities (CAN Learning), and;

- Resourcing creative projects across the state with innovative funding and developing cross-sector partnerships (CAN Doing)(CAN WA, 2013a).

In many of the towns in which CAN WA undertakes community cultural development projects, there is a relatively large Aboriginal ${ }^{1}$ population. For example, according to the 2011 census, the Aboriginal population in Quairading was $14.8 \%$, in Tammin, $12.4 \%$, in Kellerberrin, $9.8 \%$ and in Merredin, 5.7\% (vs. $2.5 \%$ nationally)(ABS, 2011). Given these demographics, coupled with the agency's commitment to social justice, CAN WA leads the way in working with Aboriginal communities in Western Australia, and through their prolonged engagement, has come to realize that a longer-term and community determined approach is required for social change (CAN WA, 2013b).

As community psychology researchers, we have accompanied CAN WA in their broad and systematic efforts to bring about social change through community cultural development, including community arts practice. In describing the work, we emphasize the iterative and generative nature of community-based research and action (Bishop, Sonn, Drew, \& Contos, 2002). We highlight the largely positive role of community arts projects in fostering participation and opening up other ways of knowing and doing. However, we also stress the need to engage critical theorizing in order to capitalize on the transformative potential of arts practice and community cultural development more broadly, and to make visible the ways in which oppression is maintained through discourse, ideology, and cultural practices in everyday ways.

\section{Community Arts Practice and Community Cultural Development}

Community arts practice is the vehicle through which community cultural development (CCD) can occur. CCD is a participative process that draws out taken-for-granted knowledge and future aspirations of a community through creative means to express, preserve, or enhance that community's culture (Madyaningrum \& Sonn, 2011; Sonn, Drew, \& Kasat, 2002). As articulated by Adams and Goldbard (2002):

In community cultural development work, community artists, singly or in teams, use their artistic and organizational skills to serve the emancipation and development of a community, whether defined by geography (e.g., a neighborhood), a common interest (e.g., members of a union) or identity (e.g., members of an indigenous group). (p. 8)

\footnotetext{
1 'Aboriginal' is used throughout this paper to denote Aboriginal and Torres Strait Islander people as CAN WA has found that local people generally express a preference to be described as Aboriginal over Indigenous. 'Noongar' as the overarching language and cultural grouping is also used in excerpts and by the agency to refer to Aboriginal people in the Wheatbelt area of Western Australia. Wadjella is also used at times; this is the Noongar term for White people.
} 
Mills and Brown (2004) have distinguished between instrumental and transformational approaches to community cultural development and community arts practice. Instrumental approaches involve using the arts as a 'tool' for educating and raising awareness of particular issues, while transformational approaches involve using "creative activity to help determine policy, negotiate shared understandings and map out solutions" (p. 8). Transformational approaches engage more explicitly with issues of power and are more aligned with the notion of critical community practice and community psychology.

\section{Community Arts, Power/Empowerment and Participation}

Participation and inclusive arts practice are central to CCD (Adams \& Goldbard, 2002; Goldbard, 2006; Hawkes, 2001; Nicolaides, Bunbury, \& Hawkes, 2012). The arts are viewed not only as end products, but also as vehicles through which community members (whether defined by geography, common interest, or identity) can engage in the joint identification and production of images, symbols, and other resources which are reflective of community visions and aspirations (Sonn et al., 2002). Thomas and Rappaport (1996) discussed local community arts projects as potential resources that provide a way to index a community's experiences and to participate in the making of "their own history, their own future, and their own identity" (p. 326).

The objectives of CCD are in line with an empowerment agenda that is concerned with the development of individual and group capacities and awareness about the social and cultural spaces in which they are situated, and that shape everyday interactions and community relations. Here, empowerment is not reduced to individual psychological dynamics, and also includes contextual or setting-level variables as well as social and political processes (Rappaport, 1994). There is a focus on transformative or second-order change, that is, changing the systems and their assumptions (i.e., power relationships)(Nelson \& Prilleltensky, 2010).

This conception of empowerment emphasizes actual increases in power (both material and symbolic), thus avoiding the cognitivist and decontextualized focus on an individual's sense of or perceptions of empowerment (Riger, 1993). By emphasizing the social structural factors, the personal is made political as opposed to making the political personal, which leads to victim blaming (Riger, 1993). Significantly, as suggested by Cornish, (2006), in determining whether a person or group is empowered (or not), it is important to specify the domain of activity in which a person or group has the power to act, because the powers and disempowerments that people and groups experience and enact are multiple and contradictory. For the purpose of this article, the focus is on the empowerment of individuals and communities, and in particular Aboriginal people/communities in the Wheatbelt, to participate in community life, whether at the level of local government in decision-making processes, or in the representations of their own community, culture, history, and perspectives. The power of Aboriginal people/communities to participate is understood as shaped and constrained by symbolic and material relations of power stemming from the ongoing history of colonization and racism.

\section{Participation, Conscientization, and Social Change}

From a community psychology perspective, participation is viewed as a key mechanism for empowerment because of its potential to foster democratic decision-making processes, to subvert traditional power relationships, promote community-engagement (Kagan et al., 2011; Nelson \& Prilleltensky, 2010) and because it is through participation that individuals 
and communities can identify social and cultural resources, which can be mobilized for social identity construction and community-making (Campbell \& Jovchelovitch, 2000; Montero, 2009; Sonn et al., 2002). While recognizing the benefits of participation and promoting participation as a key value of community psychology (Nelson \& Prilleltenky, 2010), there is also a need to attend to the symbolic and material power relations that shape and constrain opportunities for and experiences of participation. For example, Campbell and Jovchelovitch (2000) have emphasized that a social psychology of participation must take into account social representations, identities, and power. Within liberation psychology writing, it is through participation that the process of conscientization is made possible (Freire, 1972), which entails becoming aware of limiting social, political, and historical realities and acting in solidarity to transform those realities (Freire, 1972; Martín-Baró, 1994; Montero, 2009). The process of conscientization necessarily entails engagement with social representations, social identities and power.

Similarly, Christens, Hanlin, and Speers (2007) have described the importance of getting the 'social organism thinking' in efforts aimed at social change through altering the social imagination. Viewing cultural beliefs, ideology, and shared understandings as central in shaping the views that individuals hold about the systems and societies of which they are a part, they emphasize that "although individuals within systems are the bearers of a social imagination, they are not entirely individually responsible for the views they hold, or for changing them" (p. 230). They argue that the social imagination is of central importance to systems change, and that it can be altered through a dialogical view of the individual and system, movement toward greater complexity, an eye toward power relationships, and a search for connections and points of leverage (Christens et al., 2007). The notion of a social imagination emphasizes that the potential to facilitate social change "is constrained by social power - particularly the capacity to shape ideology" (Christens et al., 2007, p. 229). At the same time, it suggests that through the creation of spaces for participation in processes of shared meaning making, where cultural beliefs, ideology, and shared understandings can be made visible, deconstructed, and reconstructed, (i.e., spaces for conscientization), transformative change is always possible.

Highlighting the potential role of community arts practice in facilitating the process of conscientization, Madyaningrum and Sonn (2011) suggested that the positive outcomes associated with participation in a community arts project were associated with a project's ability to foster individual and social awareness about different groups within the broader community. Through their case study of a community arts project in a regional town in Victoria, the authors showed how participation in a community arts project could challenge social representations attached to particular social identities and show up and contribute to the transformation of unequal power relationships. For the authors, the settings created by community arts projects "become the site in which people who are differently positioned in terms of social arrangements and histories, are afforded opportunities to engage with neglected and invisible experiences and stories from within the broader community" (Madyaningrum \& Sonn, 2011, p. 367). The dual tasks of creating spaces where the voices of those marginalized are amplified and promoting receptive social environments, or 'getting the social organism thinking', were identified as necessary in achieving psychological and social transformation (Campbell, Cornish, Gibbs \& Scott, 2010). This is about creating spaces for conscientization for both the 'oppressors' and the 'oppressed'. In the following section, we describe a program of work with a community cultural development agency in Western Australia. The program of work is systematic, has been long term, multifaceted, and has evolved over time. 


\section{Community Arts Practice in the Wheatbelt}

CAN WA is the peak body for community arts and cultural development in Western Australia. The agency was founded in the mid 1980 s by a network of people committed to community arts practice, and advocacy and training in community arts and cultural development. Since that time, CAN WA has become an incorporated body and has delivered numerous training programs, arts projects, and its goals of promoting social justice have seen strong commitment to working with Aboriginal people. The fundamental role of CAN WA in rural Western Australia is to build community capacity through "affirming culture and expressing this through the arts, mentoring, and developing individuals, modeling Aboriginal community leadership, and creating opportunities for Aboriginal participation in community life" (CAN WA, 2010a). CAN WA understands the need to involve the community in processes that help them track the past, understand and explore the present, and use their imagination to help manifest the future (CAN WA, 2010a). Viewing culture, creativity, and the arts as essential for community wellbeing and as at the core of a just, diverse, and resilient society, CAN WA recognizes the strengths and resources of Aboriginal people and culture and the positive role that the arts can play in reconciliation and healing, and Aboriginal empowerment.

We have partnered CAN WA on different research projects in the Wheatbelt region of Western Australia since 2006. The first author (Christopher) is a black man who was born in South Africa, but has been living in Australia since the mid 1980s. He is a scholar/researcher in community psychology, with an interest in anti-racism, anti-oppression, and decolonization, and has been involved with the agency in different roles since the late 1990s. He started with the agency as a member of the board of management and later began to contribute by supporting the agency in documenting their work through research and evaluation (see Sonn et al., 2002). This role has continued, and he has also provided input in the form of reflective practice discussions on topics related to working in colonial contexts, researching arts practice, and community psychology. The second author (Amy) is a white Australian woman and community psychology graduate researcher originally from country Victoria, with a commitment to social justice research specifically anti-racism and whiteness studies. She became involved as a research evaluator of one of the Wheatbelt projects. Both authors are outsiders to the Wheatbelt communities and are currently based in Melbourne.

The Wheatbelt region of Western Australia comprises an area of 154,862 square kilometres, extending north from Perth to the Mid West region, and east to the GoldfieldsEsperance region. With a highly dispersed population of over 75,000, it is the third most populous area in Western Australia (Department of Regional Development and Lands, 2012). The region is made up of 43 local government areas, and approximately 160 populated towns (Department of Training and Workforce Development (DTWD), 2012). Traditionally, the Wheatbelt region has been the principal agricultural and farming heartland of Western Australia, and this continues to be the case. The region has an overrepresentation of people over the age of 65 and an underrepresentation of people between the ages of 15 to 24, which can be attributed to high levels of out-migration of young people in search of further employment, education, or social opportunities as well as an ageing population (DTWD, 2012). Within the Wheatbelt, there are four main sub-regional areas: Central East; Central South; Avon; and Central Midlands (DTWD, 2012). Much of the work we describe here has been carried out in the Central Eastern region of the Wheatbelt since early 2004, when CAN WA commenced their engagement in the region, beginning with scoping work. Within this sub-region, many of the towns have a relatively high Aboriginal population (5-15\%)(ABS, 2011), and Merredin is the regional centre. 
There is a longer and deeper story, but here we describe three community-based research projects that are part of an ongoing program of work within a particular region of Western Australia, to show how, as critical friends and as researchers to CAN WA, we have engaged in praxis, in reflecting on actions with the purpose of contributing to the 'doing' of critical and liberating community cultural development.

\section{Arts Practices as Research and Action: Drawing out Community Empowerment}

The establishment of the Kellerberrin Indigenous Arts and Cultural Development Unit (KIACDU) in 2006, marks the starting point of CAN WA's engagement with communities in the Central Eastern Wheatbelt (beyond 'scoping'). Following an earlier feasibility study, the KIACDU was identified as the most effective way to support Aboriginal arts and cultural development, in a way that was self-determined by and empowering for the Aboriginal communities in the region (see Green \& Sonn, 2008).

The first author's initial involvement in the work in the Wheatbelt was in the form of a collaborative research project aimed at exploring community members and other key actors' perceptions of the KIACDU, the role of arts programs in the community and to learn how best non-Indigenous agencies can support Aboriginal community empowerment (Green \& Sonn, 2007). The process of determining how best to do the research in a respectful and appropriate manner was negotiated with the Aboriginal KIACDU officers, Aboriginal people in Kellerberrin, the researchers and an artist. Following discussions it was agreed that the team would run arts workshops with different groups in the town and also use participant observation to gather data.

Three workshops were developed including a two-day photography workshop for young women who had participated in a previous course delivered by CAN WA and who wanted to learn more. The women learnt about light, color, and patterns, and they were asked to take pictures that would reflect what their town meant to them. A second workshop was developed for older women (six) who were associated with a local Aboriginal group, Yok Yoruk, who mostly sew. The women were interested in learning about printing and making their own designs. They were also asked to make something that represented their town. A third workshop was designed for men, but this did not eventuate and instead the researcher accompanied the group on a tour of special sites, followed by a discussion of their hopes for their town.

Data was gathered using participant observations at different events in the town and interviews with those who participated in the workshops, community leaders, artists who delivered workshops, and CAN WA staff. The arts products were displayed at the 2008 Badjaling Cultural Festival. Badjaling is an Aboriginal community and the site of an Aboriginal reserve from the mission days. The festival is open to everyone, but is attended by mostly Aboriginal people from different towns in the region. Through participant observation and informal conversations with Kellerberrin community members, it became evident that the relationship between the Aboriginal and non-Indigenous people within Kellerberrin had been tense. This is reflected in the quotation from an Aboriginal CAN WA worker from the town.

Keith (Aboriginal CAN WA worker and resident of Kellerberrin): I think it's just a lack of understanding and ignorance from the Wadjella (non-Indigenous) community towards Aboriginal people. Aboriginal people are visual people. They like to be seen out in the streets. In terms of their drinking, there's a core group of people who drink a lot in 
Kellerberrin that may represent maybe 5 , maybe $10 \%$ of people. That's their choice. What it comes down to is choice, but don't put all Aboriginal people in the same basket. Don't paint us with the same brush because we're all different; but that's been the perception of the Wadjella community. Also that comes back to historical factors, historical things that have happened in the region. There's been a lot of racial tension of course and with the previous government legislations and the Stolen Generation in the mission days for example. You know the power of men and particularly white men in communities quite often on councils, you'll see a whole heap of white men in their 40s, $50 \mathrm{~s}$ and $60 \mathrm{~s}$ who sit on the council and these people are firmly entrenched with their views about Aboriginal people and Aboriginal issues.

There was also a sense that nothing much happened in Kellerberrin before CAN WA established the KIACDU. These perceptions are conveyed in the quotation below from an Aboriginal CAN WA staff member, another local resident.

Sandy: I always say dormant for some reason because before, everything was dormant and now everything is really busy and it's like a volcano waiting to erupt, all these good things. When we had the first art workshop through CAN WA down at CDEP [Community Development and Education Program] centre you could just feel this energy and buzz that people were like, "Oh, I could do that" or "I could do more". It was just a really good feeling. It was like everyone was on drugs or something but it was just a natural high and they were all buzzing about...

Data analysis focused on the key ways in which participation in community arts was experienced as empowering; the processes involved in community empowerment and the challenges of working together across racialized divides. Given space constraints, we discuss each of these key themes briefly, with illustrative excerpts (see Green \& Sonn, 2008; Sonn \& Quayle, 2012).

'Empowerment through arts', included learning new skills, having fun, healing by sharing stories and dealing with social issues. Participants highlighted the healing and fun dimensions of arts participation; while those involved in the facilitation of the project emphasized the potential role the arts can play in terms of training and skills development, as well as dealing with social issues.

Deidre (Aboriginal community member): Even if it's just a workshop or barbecue or a film night it's good because it brings the togetherness that's been there for the Noongar communities for a long time ('Having fun').

Cathy (Aboriginal community member): We try to encourage the women, there's a group of women here that like to sit down and drink every day. One of the things we have been trying since we started is try to get those young women involved in things so that they can see there's more to life than just drinking every day ('Dealing with social issues').

Sandy (Aboriginal CAN WA worker): I know my partner, he was very stressed and everything when we came up here and we did the workshop around the same time I think that we moved up and he just sat there all day just painting. It was just quite amazing that he actually sat there and did it all and I have never seen him sit there so patient and wanting to finish this damn picture but he did it in two days. Certainly I don't know to what degree it helps them with 
their healing and that but you can see some sort of sense of pride and a sense of the weight lifting off their shoulders ('Healing through sharing').

'Community empowerment' related to the processes and practices were considered central to transformative community practice. Community empowerment included operational domains or processes of: 'gaining trust', 'being responsive', 'providing resources and expertise', 'letting go' (of power and control), 'making connections', and 'collaboration with other agencies'.

Deidre (Aboriginal community member): Good, well I went to school with Theresa so I have a good connection with Theresa. Having her there too, having that back-grounding with us as well so she knows everyone here and everybody knows her. It's always a good thing because sometimes it can take longer to develop if you have a stranger but building up trust with Aboriginal communities it takes a lot because of past things and CAN WA has that ('Making connections').

Keith (Aboriginal community member and CAN WA worker): It's about building that trust and of course all that has come about because of us being Aboriginal people on the ground in the Indigenous community. I think it would have been a different story if we'd had non-Aboriginal people working in the Unit. It's about our relationships socially outside of what we do on the ground here. It's about our relationships socially, ...I live in another town, yet there are social links between the families and also family links, historical links as well between those communities in the region and just knowing people before the Unit was created ('Gaining trust').

Through this research, the different dimensions and processes that were conceptualized as empowering, or as facilitating community empowerment, were distinguished. Yet, there were significant challenges to working together, which highlighted power relations and the coming together of differently positioned knowers (that is, Aboriginal and non-Indigenous participants, community members and artists) and knowledge in social settings. The following excerpts reflect some of the tensions from the vantage points of non-Indigenous CAN WA staff members:

Rachel (non-Indigenous CAN WA worker): Yeah, so that was probably the most challenging, and also on the days where it was pay day, where people got on it [alcohol] and then we're not up for attending the next day, so that was also an issue for us where we then changed the actual schedule so it didn't fall on the day after pay day.

Interviewer: How did it feel that they wouldn't turn up because it had been pay day the day before, when you first experienced it?

Rachel: Yeah, well I suppose it's disappointing, it's always disappointing. That's my main, I suppose my main issue in all of my programs at the moment, is the fact that you're working with a group that often don't turn up. Again, that's a feeling that I had for that particular group that I also have, across the board when people don't turn, it feels disappointing, because you feel like you've put in a lot of energy and you question whether it's worth it obviously sometimes or whether it's the right thing or whether it's what they need or want or... 
Louise (non-Indigenous CAN WA worker): Well sad I guess in the sense that there's a lot of complacency, there's a lot of spirit and a lot of guts and when you hear someone speak and they've got a lot of passion but then in their actions and their daily activities it contradicts maybe what they say. Like you said, we are from different worlds, maybe knowing the amount of alcohol that's in the community and the domestic spaces that some of the girls have to go to or live in or just accept, things like that, I personally found it sad. ....

In the above quotations the non-Indigenous CAN WA staff members are reflecting on the challenges that exist within the community, such as excessive alcohol use, which makes them feel sad and disappointed, and from their standpoints, reflect a sense of complacency within the Aboriginal community. At the same time, they recognize that Aboriginal and nonIndigenous people are 'from different worlds', and that there are strengths (that is, 'spirit', 'guts' and 'passion'). These reflections highlighted some of the deeper challenges of working in contexts characterized by social inequality and a longer history of racism. One of the key recommendations that came from this research was that the CAN WA should continue to engage in dialogue and critical reflection about its intercultural practice and commitment to anti-racism. A central part of this would include ideological and cultural critique with a focus on making visible race privilege and how it can be produced in dominant narratives including understandings of issues, as a means of drawing attention to how societal inequalities can be reproduced in our own practices, despite the best of intentions.

\section{Voices of the Wheatbelt: Making the Ordinary Extraordinary}

Following on from the establishment of the KIACDU and these initial CCD activities was 'Voices of the Wheatbelt', CAN WA's largest community arts project to date. Funded under the Stronger Families, Stronger Communities, Local Answers strategy of the Australian Government department: Families and Housing, Community Services and Indigenous Affairs (FaHCSIA), 'Voices' set out to build and strengthen relationships with and between families and across generations, including relationships between Aboriginal and non-Indigenous people in four different towns of the Eastern Wheatbelt: Merredin, Tammin, Quairading and Kellerberrin. The creative means of self-expression that were used for community building, included photography and songwriting, which were seen as media through which people can represent their experiences, and name and act upon their social world (Purcell, 2007). The photography programs were delivered via high schools and primary schools over three terms of the 2008 school year. Members of the broader community also participated in workshops and subsequent community exhibitions that were held across different towns and also in the port city of Fremantle. The photo exhibition in Fremantle was held at a gallery over a one-week period and was attended by over 500 members of the general public. The data sources used to evaluate the overall program included: artist program reports, feedback sheets, photo elicitation, and photo naming workshops, newsprint and other media reporting, as well as telephone interviews (see Sonn 2009).

The 'Voices' evaluation (Sonn, 2009), reported the benefits of participation in the project across multiple levels. These benefits were: personal growth, acquiring technical skills and knowledge about photography, breaking down the silence between communities and improving social relations. This included young people connecting with teachers and adults in different ways and as equals as well as opportunities for new relations between Aboriginal and non-Indigenous people to be forged. A teacher in one of the towns noted:

The project strengthened relationships between Aboriginal and non-Indigenous communities. The focus was successful in exploring local culture, diversity, 
relationships and reconciliation. Students accessed West Australian Aboriginal and non-Aboriginal artists and students gained skills in photography and music. All students had the opportunity to travel to Badjaling Mission Open Day to show case their creative artwork developed by them that celebrated the local cultures and increased collaborative partnerships.

A community member also commented: "older and younger people, varying age groups, and people new to the community were brought together". Another resident from the same town stated: "It got people together again and we need to belong in such a small place. We need to meet up, everybody becomes friends, 'fellowship'- it didn't matter about age".

Another spin off from this project was the creation of new settings such as photography clubs as well as enthusiasm within the community about the possibilities of such settings to be created. There were also deeper outcomes, in particular the opportunity for people to (re)present their communities to other people, and to turn the ordinary into something new, which also facilitated the sharing of stories across communities. Turning the ordinary into something new to be revalued and enjoyed is not only central to shifting ways of seeing, but also for sharing and vision, and to begin to imagine doing things together into the future. Examples of this included expressing the significance of the environment to young people, and hearing about Aboriginal stories of place and belonging, stories that were often unknown by the non-Indigenous community, and not present in dominant stories about the history of the towns.

By and large, people reported positive experiences of participation in the project. While matters of racism were not explicitly addressed as part of the project, the differential access to social, cultural and economic resources became evident throughout the process. For example, in the stories told by young people about their future aspirations, non-Indigenous young people spoke about the taken for granted next steps of going to boarding school in the city, whereas negative scripts hampered Aboriginal young people, who were not expected to complete school. While it was and is, difficult to shift some of these broader societal narratives and community perceptions, CAN WA continued to reflect on its own practices, which included providing opportunities for local Aboriginal people to lead the projects and to engage with local Aboriginal people at all stages of the project. Without the cultural skills and knowledge of Aboriginal people, co-actors for community building, the project would not have been nearly as effective (Sonn, 2009).

While this was an extremely valuable project, particularly in highlighting the resources within the town and specifically the Aboriginal community, as well as CAN WA's commitment to the region, the agency recognized that the potential of their community arts practice would be limited without broader level structural change, which would necessarily entail altering the social imagination (Christens et al., 2007) and developing strategic partnerships with those in positions of power.

\section{The Strategic Partnership Initiative: Building Alliances}

The Strategic Partnership Initiative (SPI) was the next initiative that developed out of CAN WA's evolving relationships with the people in the Central Eastern Wheatbelt. The SPI reflected an explicit engagement with the need for structural change, and in particular the creation of a receptive social environment within which Aboriginal people were empowered to participate, with its key focus being to provide a strong foundation for future partnerships and initiatives between Aboriginal people and local governments in the region. This was to be achieved through: 
- Engagement with and participation in community celebration and the development of arts and cultural activities;

- Celebrating and acknowledging contemporary and traditional expressions of Noongar culture as central to local identity and sensitivity to place; and

- Increasing community-wide understanding and awareness of the values and perspectives of Noongar people (CAN WA, 2010b).

\section{Background to the SPI}

In 2008, as part of their cultural planning strategy, CAN WA began a process aimed at facilitating local Aboriginal consultation and contribution to a proposed initiative aimed at exploring the development of cultural tourism opportunities in the region (Sonn et al., 2002). CAN WA staff, including Aboriginal people from the region, believed that there were potential opportunities available for the Aboriginal community in claiming and developing their own stake in the local tourism industry, with Aboriginal stories about place to be central. This was perceived as a way of ensuring that the cultural significance of different sites in the region, and Aboriginal connection to place was recognized and celebrated. However, through the process of community consultation, there was resistance from the local Aboriginal community about the pursuit of 'joint cultural tourism opportunities'.

Aboriginal community members expressed a range of concerns about the development and management of cultural tourism operations and about the protection and acknowledgment of many other culturally significant sites in the region. There was significant frustration around the lack of consultation to date and deeper conversations revealed a longer history of poor relations between local government authorities and Aboriginal people (CAN WA, 2010b). While the pursuit of joint tourism opportunities was worthwhile from the perspective of both CAN WA and local government representatives in the region for both cultural and economic development, it raised alarm bells for Aboriginal people, revealing significant levels of mistrust within the Aboriginal community of local government and other 'Wadjella' agencies. The expressed fears about cultural appropriation reflect a history of cultural dispossession and policies of assimilation, which have been central to colonization and ongoing processes of racialization (Dudgeon, Mallard, Oxenham, \& Fielder, 2002; Smith, 2012). CAN WA therefore identified the need for significant groundwork in terms of relationship building between the local government agencies and Aboriginal people to be done before tourism opportunities could be pursued, and for determining if cultural tourism was in fact something that Aboriginal people in the region wanted for their community in the first place. Thus, the key focus of the original initiative ('Seeding creativity') -- the exploration of local connection to the Granite outcrops, was expanded to include the three key aims of the SPI previously outlined.

While in discussions with CAN WA, local government agency representatives have acknowledged the need to engage the whole community and take active steps to improve relationships with Aboriginal people in the different towns, it became clear that some of the assumptions underlying local government talk about inclusion of the 'whole community' and their stated commitment to improving relationships needed to be interrogated. In particular, questions needed to be asked about what participation of the Aboriginal community would actually look like in the context of joint tourism opportunities, that is, participation on whose terms and for whose benefit (Cornish, 2006)?

The background to the development of the SPI is important to share as it reflects CAN WA's grounded engagement with praxis, and the willingness of the agency to change course and 
to question some of the underlying assumptions informing their practice. Indeed in reflections on the initial planning of the initiative (as originally conceived), one CAN WA staff member, while recognizing the potential ramifications associated with funding requirements, emphasized that she just could not go ahead with the initial project as planned, as it did not feel right. The agency needed to be flexible; and accountability to the Aboriginal community and the relationships that had been developed over time was foregrounded. This reflective praxis was testament to the relationships that had been developed with Aboriginal people in the communities, and the openness to being vulnerable demonstrated by CAN WA staff. From our perspective, this experience reflected the episteme of relatedness (i.e., relational ethics) in practice (Montero, 2007), and ultimately eventuated in a more appropriate initiative moving forward: The Strategic Partnership Initiative (SPI).

\section{The SPI}

As the initiative progressed, it had became increasingly clear that facilitating awareness of Aboriginal culture, values and perspectives also meant acknowledging the history and continuing legacy of colonization and racism and the taken-for-granted power and privilege associated with whiteness, that is, dominant social group membership within the Australian context. Therefore, in addition to the different community arts projects, the SPI saw CAN WA play an active role in brokering relationships between Aboriginal people and local government. As part of this, there was an identified need for research to examine the symbolic barriers to partnership between communities. First we outline the community arts projects undertaken within the broader initiative followed by a focus on the research component of the initiative.

\section{The Arts Practice}

In other research projects that CAN WA has initiated, the focus has been on conceptualizing and exploring the benefits of arts practice in communities within an empowerment framework (See e.g., Sonn et al, 2002; Green \& Sonn, 2008; Sonn, 2009). The SPI continued this engagement on the ground to promote inclusion through arts practice with several projects undertaken including a variety of oral history based projects. For example 'Bush babies' where Aboriginal people born at Badjaling reserve and the Aboriginal midwives that delivered them were honored in a story sharing day; 'Noongar Voices of the Central Eastern Wheatbelt', a three part Radio documentary series; a community performance 'The ExtravANTGAnza', which featured as part of the Keela Dreaming festival; and the 'Djuran excursion', where Aboriginal elders took Aboriginal students for a day of traditional cultural skills at the Djuran mission site, a place where many of the Elders were born and lived (Sonn \& Quayle, 2011). As part of this excursion, an oral historian brought along recording equipment and the students and Elders were able to interview each other throughout the day (CAN WA, 2010b). These different projects have been highly successful as indicated by the coverage and feedback from people who participated (See e.g., CAN WA, 2011a; CAN WA, 2010c), and illustrates the importance of storytelling for reclaiming silenced stories. As evaluators of the SPI, we recommended that these projects should be encouraged because they are vital to providing spaces for joint participation and are examples of communities telling their own stories, which are important for cultural continuity and for change.

The community arts projects undertaken as part of the SPI fostered opportunities for participation, voice and connectedness were limited in terms of achieving the types of social and economic change that the agency had imagined. It was therefore important to begin to examine the broader ideological context within which the community cultural development efforts were situated. 


\section{The Research: Surfacing Normativity}

CAN WA recognized a need for structural change at the level of local government and believed that they could play a role in facilitating this change towards inclusive governing for the whole of the community. However, the agency needed to gain a deeper understanding of the symbolic barriers to working together. It was at this point that CAN WA commissioned research into the symbolic barriers to local government and the Aboriginal community working together, that is, to inclusive community governing.

As community psychology researchers influenced by critical race theory and whiteness studies, we proposed that there was a need to identify and critically examine the different social and symbolic resources that differently positioned groups of people draw on to understand and explain the history of poor relations between communities. In consultation with CAN WA, we initiated a qualitative study to speak with Aboriginal community members and local government representatives, to explore the common sense understandings of self, other and society, governing everyday practices and processes including interactions between these differently positioned groups of people. We recognized the persistence of dominant community narratives in affording blame and merit and in constructing how problems were to be solved, and were interested in explicating these common sense narratives as part of CAN WA's critical praxis.

In this iteration of the work (as researchers partnering CAN WA in their praxis), we introduced critical race theory and whiteness studies to help historicize and politicize the understandings of barriers that differently positioned people hold (Frankenberg, 1993; Green, Sonn \& Matsebula, 2007; Ladson Billings, 2003). We focused on the symbolic barriers to partnership and employed critical discourse analysis to analyze interview data collected from semi-structured conversational style interviews with non-Indigenous local government representatives (Chief Executive Officer's - all male, and Community Development Officer's, all female; all non-Indigenous) across four towns and Aboriginal Elders and community members across three shires. As reported elsewhere (Quayle \& Sonn, 2013), Aboriginal and non-Indigenous understandings of barriers to working together and the causes of the history of poor relations were vastly different, reflecting (and reproducing) historical power asymmetries. The discourses identified in local government and Aboriginal participant's talk about barriers to partnership, are displayed in Table 1, with illustrative excerpts provided. Due to space constraints, we only provide a brief overview of the different accounts and implications for partnership.

The interrelated discourses identified in local government talk about barriers to partnership were 'abstract liberalism', 'cultural blame' and 'silencing and not acknowledging the past'. Drawing from Bonilla-Silva (2006), and his central tenets of color-blind racism, 'Abstract liberalism' involved local government representatives drawing heavily on the rhetoric of liberalism (i.e., egalitarianism, individualism and meritocracy) to speak about barriers to partnership and the history of poor relations between communities. 'Abstract liberalism' reflected the overriding normativity of the non-Indigenous participants and worked to construct a particular understanding of how Australian society (and its citizens) does (and ought to) function. Local government representatives also drew on the discourses of 'culture blame' and 'silencing and not acknowledging the past' to explain barriers to partnership (See Quayle \& Sonn, 2013), which can be understood as the inevitable consequence of the construction of the world achieved through 'Abstract liberalism' (i.e., If we live in a post race society, and every individual is responsible for their own life course, then the problem must lie with 'them'). 
Table 1

Discursive Resources Mobilized to Explain Barriers to Partnership

Non-Indigenous participants (local government representatives)

Abstract liberalism "Council tries to deal with everyone equally and fairly, and not overly or over emphasize one part of the community over another and be very careful there's no separation"

"It upsets me that people aren't utilizing their full potential"

Culture blame "There's this collective history slash baggage within their own families, the mobs or whatever else so it's hard for white people to understand, cos we haven't got 40,000 years of history living in the patch or being in the region or whatever else"

"Its just they sit back and they want things done for them"

Silencing and not "um some of its baggage from like, just because there was a stolen acknowledging the generation and stuff like that but there were a lot of white back in past the day too that were taken away from their families as well"

Aboriginal participants

Disregard

"What do you know about your local Aboriginal community? That they're lazy, no-hopers, drunks, some of that will be the answers

"You have to be white to be right"

Dispossession "It's a whole load of bringing in something that wasn't there, you know? And hence we've got half our population wiped out. We're lucky to be here today, you know?"

Being

misunderstood

"With cultural awareness, they need to go back and look at things that happened way before white men came to this country. How they lived in harmony with the land and with everything else...It's not our fault"

"Don't give us the white man's history, they've got to put the black man's history in there too"

Cultural mistrust "I put in for a job back in the 90's, and I never heard nothing and I never worried about it again. And I think a few other family members have also put in there and they, you know you never hear nothing from them".

"With all the information you fellas are getting, we're not going to see the outcome 
The discursive resources identified in local government talk echoed Bonilla Silva's (2006) notion of color-blind racism, which he argued has emerged in the post civil rights era to defend the contemporary racial order. Consisting of four central tenets: Abstract liberalism, culture blame, minimization of racism and naturalization, the ideology of color-blind racism exemplifies the power the dominant culture has "to define and articulate knowledge in which they may distort, overlook, exaggerate and in turn perpetuate and extend ignorance in a number of ways" (Green et al., 2007, p. 399). While seemingly benign, the common sense understandings of local government worked to further marginalize and exclude Aboriginal people, but did not necessarily involve malice or 'intent to be racist'. This research highlighted the need to disrupt dominant cultural narratives that have exclusionary effects, as it is through reworking these that we begin to create new stories for partnerships.

Aboriginal participants offered vastly different explanations, which were in direct contrast to these decontextualized and apolitical constructions offered by non-Indigenous participants. Aboriginal people, without exception, spoke of being disregarded and treated as second class citizens, misrecognized and misunderstood, dispossessed, and as a consequence, as not trusting the institutions of 'White/Wadjella' society. The perspectives offered by Aboriginal people problematized local government assertions that they were 'there for everyone', and in so doing may contribute to awakening a sense of injustice in those in positions of authority within the community, and encourage greater critical reflection and engagement with issues of power in other organizations such as local government and within the broader non-Indigenous community generally. Ideally this would mean that the lessons learned through and enacted in CAN WA's praxis could be transferred to other settings, where organizational transformation is required. Importantly, this would mean providing opportunities and spaces, structures, practices, and processes that support such critical dialogue.

At this particular point, there are feedback processes being undertaken. One of these was a Creative Think Tank, which involved feeding back this program of work to multiple government and non-government agencies and funding bodies (see CAN WA, 2011b). The intention was to mobilize those in positions of power and privilege to create receptive social environments within which Aboriginal people could be empowered to participate. In addition, the research report prepared for the organization into symbolic barriers to working together is in the process of being transformed into a 'community discussion paper' with the idea of feeding back to the broader Aboriginal and non-Indigenous community including local government, as part of the process of critical community cultural development. This translation of the research to the community is challenging given the sensitive nature of the issues of race, racism and whiteness, and the defensiveness that often comes with discussions of race privilege. However these conversations are important to have. We have drawn on whiteness studies in particular, because from our perspective, while it implicates everyone in racism, it does so in a way that does not individualize the issue of racism, and therefore does not point fingers at individual 'racists'. At the same time, it is confronting and often resisted. Currently, we are planning in consultation with CAN WA, to develop another think-tank, where the findings from the research ('community discussion paper') can be fed back in a constructive way that facilitates community dialogue about the issues. This is also challenging because of other demands put on the agency, and competing priorities.

\section{Discussion}

In this article we set out to describe critical community practice in the context of CCD program in a rural region in Western Australia. A major focus of this work has been aimed at promoting participation and social inclusion of Aboriginal people within local communities, 
which are seen as a microcosm of the broader society. We described three specific arts projects that were part of a broader program of community cultural development. These initiatives were the outcomes of processes of negotiation with local people in different towns and sought to build on the strengths of Aboriginal communities in the region, while at the same time, responding to the ongoing social inequality characterizing the lives of Aboriginal people in these rural communities.

The arts projects with the CCD methodology themselves have been overwhelmingly successful in terms of encouraging participation, promoting voice and even fostering cultural tourism with people attending exhibitions, festivals and shows. While the arts have been successful, CAN WA has needed to be reflective and responsive to experiences and needs on the ground. They have had to respond to the politics and the multiple actors within local communities and understand the importance of investing in those communities in projects and through the employment of local people as well as the provision of training and mentoring opportunities to strengthen Aboriginal leadership. Importantly, they have also had to clearly articulate their values and principles, including the commitment to Aboriginal empowerment, reciprocity, and valuing of different ways of knowing and being to make use of creative means for promoting individual, interpersonal, and political change. This work has not been piecemeal. Rather, it has been systematic and participatory, and has opened opportunities for new solidarities between agencies, community members and researchers and forming solidarities is an important strategy for change through community praxis.

As part of the critical reflection on action, and our community psychology practice, we have participated as researchers and critical friends and introduced conceptual and methodological resources from liberation and community psychology into the discussions. On the other hand, the experiences on the ground have reflected the importance of situated knowing, the need to understand power, and significantly, the need for an epistemological stance that views people and systems as interdependent. The circuits of dispossession take place in everyday ways, and are sanctioned by institutions and spaces that subscribe to monological views of the world (Rose, 2004).

As a central part of changing the social imagination, CAN WA has sought to support Aboriginal individuals and communities through participatory methodologies, but the agency has also recognized the need to transform the broader social structures, ideologies and discourse, which perpetuate inequalities and thus contribute to the continuity of coloniality. This critical praxis has therefore required intervention at the individual (psychological), structural, as well as the symbolic domain in an iterative and generative way (Bishop, et al, 2000); it is ongoing, and still being thought through and developed within this particular town, a local yet global, context. The iterative and generative nature of critical praxis involves negotiating history and politics of identity and inter-group relations, that is, dealing with the history of dispossession and displacement and its continuing legacy at a structural, institutional, interpersonal and intra-psychic level, which requires multiple levels of intervention.

Contact Information:

Christopher C. Sonn

College of Arts

Victoria University

PO Box 14428

Melbourne, Victoria, 8001

Email: Christopher.sonn@vu.edu.au 


\section{References}

Adams, D., \& Goldbard, A. (Eds.). (2002). Community culture and globalization. New York: The Rockerfella Foundation.

Australian Bureau of Statistics (2011). National Regional Profile 2007-2011. Accessed 20 June, 2013 from:

http://www.ausstats.abs.gov.au/ausstats/nrpmaps.nsf/NEW+GmapPages/national+r egional+profile.

Bishop, B. J., Sonn, C. C., Drew, N. M., \& Contos, N. E. (2002). The evolution of epistemology and concepts in an iterative-generative reflective practice: The importance of small differences. American Journal of Community Psychology, 30(4), 493-510.

Bonilla-Silva, E. (2006). Racism without racists: color-blind racism and the persistence of racial inequality in the United States. Lanham, MD: Rowman and Littlefield.

Burton, M., \& Kagan, C. (2005). Liberation social psychology: Learning from Latin America. Journal of Community \& Applied Social Psychology, 15(1), 63-78.

Campbell, C., Cornish, F., Gibbs, A., \& Scott, K. (2010). Heeding the push from below: How do social movements persuade the rich to listen to the poor? Journal of Health Psychology, 15(7), 962-971.

Campbell, C., \& Jovchelovitch, S. (2000). Health, community and development: Towards a social psychology of participation. Journal of Community \& Applied Social Psychology, $10(4), 255-270$.

Community Arts Network Western Australia (CAN WA). (2010a). Our vision. Retrieved May 6, 2013 from: http://www.canwa.com.au/about-us/vision/

CAN WA. (2010b). Seeding Creativity in the Wheatbelt: CAN WA Strategic Partnership Initiative interim report. Perth: CAN WA.

CAN WA. (2010c). Noongar Voices paints a unique picture of Wheatbelt life: Radio documentary series Noongar voices of the Central Eastern Wheatbelt to air on ABC Radio National. Retrieved February 10, 2012 from http://www.canwa.com.au/productions/past/resources/MR_Noongar-Voices-paints-apicture-Wheatbelt-life.pdf

CAN WA. (2011a). Moornjukun - 'Black Sisters': Recording the stories of the Badjaling bush babies and their Noongar midwives. Perth: CAN WA.

CAN WA. (2011b, March). Discussion Paper: CAN WA creative think tank. Paper presented at CAN WA's Creative Think Tank. Perth, CAN WA.

CAN WA. (2013a). Welcome to Community Arts Network. Retrieved June 202013 from http://www.canwa.com.au/

CAN WA. (2013b). Our history. Retrieved June 20 from http://www.canwa.com.au/aboutus/history/ 
Christens, B. D., Hanlin, C. E., \& Speer, P. W. (2007). Getting the social organism thinking: Strategy for systems change. American Journal of Community Psychology, 39(3-4), 229-238. doi: 10.1007/s10464-007-9119-y

Cornish, F. (2006). Empowerment to participate: A case study of participation by Indian sex workers in HIV prevention. Journal of Community \& Applied Social Psychology, 16, 301-315.

Davidson, H., Evans, S., Ganote, C., Henrickson, J., Jacobs-Priebe, L., Jones, D.L., Reimer, M. (2006). Power and action in critical theory across disciplines: Implications for critical community psychology. American Journal of Community Psychology, 38(1-2), $35-49$.

Department of Regional Development and Lands (2012). Spotlight on the Wheatbelt. Retrieved June 20, 2013 from http://www.regionalspotlights.com.au/SpotlightHomeWheatbelt.aspx

Department of Training and Workforce Development. (2012). Wheatbelt workforce development plan 2013-2016. Retrieved June 20, 2013 from http://www.dtwd.wa.gov.au/dtwd/detcms/navigation/category.jsp?categoryID $=1347$ $\underline{5135}$

Dudgeon, P., Mallard, J., Oxenham, D., \& Fielder, J. (2002). Contemporary Aboriginal perceptions of community. In A. T. Fisher, C. C. Sonn \& B. J. Bishop (Eds.), Psychological sense of community: research, applications and implications (pp. 247270). New York: Kluwer Academic/Plenum.

Frankenberg, R. (1993). White women, race matters: The social construction of whiteness. Minneapolis, MN: University Of Minnesota Press.

Freire, P. (1972). Pedagogy of the oppressed. Ringwood: Penguin.

Goldbard, A. (2006). New creative community: The art of cultural development. Oakland, CA: New Village Press.

Green, M. J., \& Sonn, C. C. (2008). Drawing out community empowerment through arts and cultural practice. Perth: CAN WA.

Green, M. J., Sonn, C. C., \& Matsebula, J. (2007). Reviewing whiteness: Theory, research, and possibilities. South African Journal of Psychology, 37(3), 389.

Hawkes, J. (2001). The fourth pillar of sustainability: Culture's essential role in public planning. Melbourne: Common Ground.

Henderson, P. (2007). Introduction. In H. Butcher, S. Banks., P. Henderson., \& J. Roberston (Eds.), Critical community practice (pp. 1-16). Bristol: The Policy Press.

Kagan, C., \& Burton, M. (2000). Prefigurative action research: An alternative basis for critical psychology. Annual Review of Critical Psychology, 2, 73-87.

Kagan, C., Burton, M., Duckett, P., Lawthom, R., \& Siddiquee, A. (2011). Critical community psychology. West Sussex: John Wiley \& Sons. 
Ladson-Billings, G. (2003). It's your world, I'm just trying to explain it: Understanding our epistemological and methodological challenges. Qualitative Inquiry, 9(1), 5-12.

Madyaningrum, M. E., \& Sonn, C. (2011). Exploring the meaning of participation in a community art project: A case study on the Seeming project. Journal of Community \& Applied Social Psychology, 21(4), 358-370.

Martín-Baró, I. (1994). Towards a liberation psychology. In A. Aron \& S. Corne (Eds.), Writings for a liberation psychology: Ignacio Martín-Baró (pp. 17-32). Cambridge, MA: Harvard University Press.

Mills, D., \& Brown, P. (2004). Art and wellbeing. Sydney: Australian Council for the Arts.

Montero, M. (2007). The political psychology of liberation: From politics to ethics and back. Political Psychology, 28(5), 517-533.

Montero, M. (2009). Community action and research as citizenship construction. American Journal of community Psychology, 43(1), 149-161.

Montero, M., \& Sonn, C. C. (2009). Psychology of liberation: Theory and applications. New York: Springer.

Nelson, G., \& Prilleltesnky, I. (2010). Community psychology: In pursuit of liberation and well-being (2nd ed.). New York: Palgrave Macmillan.

Nicolaides, S., Bunbury, B., \& Hawkes, J. (2012). Growing communities: Arts and culture in local government. Perth: CAN WA.

Purcell, R. (2007). Images for change: Community development, commnity arts and photography. Community Development Journal, 44, 111-122.

Quayle, A.F., \& Sonn, C.C. (2013). Explicating race privilege: Examining symbolic barriers to Aboriginal and non-Indigenous partnership. Social Identities: Journal for the Study of Race, Nation and Culture. Doi: 10.1080/13504630.2013.796881.

Rappaport, J. (1994). Empowerment as a guide to doing research: Diversity as a positive value. In E.J. Trickett, R.J. Watts \& D. Birman (Eds.), Human diversity: perspectives on people in contexts (pp. 359-382). San Francisco: CA: Jossey-Bass.

Riger, S. (1993). Whats wrong with empowerment. American Journal of Community Psychology, 21(3), 279-292.

Rose, D. B. (2004). Reports from a wild country: Ethics for decolonization. Sydney: University of New South Wales Press.

Smith, L. T. (2012). Decolonizing methodologies: Researching and indigenous Peoples (2 ${ }^{\text {nd }}$ ed.). London: Zed Books.

Sonn, C. (2009). Voices of the Wheatbelt project: An evaluation study, In Community Arts Network WA, Naked practice: outcomes of two community arts projects in regional Western Australia (pp. 70-100). Perth: CAN WA. 
Sonn, C.C., \& Quayle, A. (2011). Barriers To participation: Exploring issues in partnership formation between Aboriginal people and local government. Unpublished Report. Perth: CAN WA.

Sonn, C., \& Quayle, A. (2012). Community psychology, critical theory and community development in indigenous empowerment. In D. Bretherton \& N. Balvin (Ed.), Peace psychology in Australia (pp. 261-282). New York: Springer.

Sonn, C. C., Drew, N. M., \& Kasat, P. (2002). Conceptualising community cultural development: The role of cultural planning in community change. Perth: CAN WA.

Thomas, R.E., \& Rappaport, J. (1996). Art as community narrative: A resource for social change. In M.B. Lykes, R. Liem, A. Banuazizi, \& M. Morris (Eds.), Unmasking social inequalities: victims, voice and resistance (pp. 317-336). Philadelphia, PA: Temple University Press.

Watkins, M., \& Shulman, H. (2008). Toward psychologies of liberation. Basingstoke, UK: Palgrave MacMillan.

Watts, R. J., \& Serrano-Garcia, I. (2003). The quest for a liberating community psychology: An overview. American Journal of Community Psychology, 31(1), 73-78. 